\title{
Impact of the Optimal Respiratory System Dynamic Compliance Strategy for Titrating Positive End-Expiratory Pressure on the Prognosis of Acute Respiratory Distress Syndrome in Children
}

\author{
Xie Youjun ${ }^{1,}$, Mo Wugui ${ }^{1}$, Wei Yue ${ }^{2}$, Wei Rong ${ }^{1}$, Tang Yupeng ${ }^{1}$, Fu Jun ${ }^{1}$, Lu Gongzhi ${ }^{1}$ \\ ${ }^{1}$ Department of Pediatric Intensive Care Unit, Guangxi Maternity and Child Health Hospital, Nanning, China \\ ${ }^{2}$ Department of Preventive Medicine, Guangxi Maternity and Child Health Hospital, Nanning, China \\ Email address: \\ xieyoujun55@163.com (Xie Youjun),mwg188@163.com (Mo Wugui),215810448@qq.com (Wei Yue),15177100102@163.com (Wei Rong), \\ 188040665@qq.com(Tang Yupen),176447884@qq.com(Fu Jun),310416071@qq.com (Lu Gongzhi) \\ ${ }^{*}$ Corresponding author
}

To cite this article:

Xie Youjun, Mo Wugui, Wei Yue, Wei Rong, Tang Yupeng, Fu Jun, Lu Gongzhi. Impact of the Optimal Respiratory System Dynamic Compliance Strategy for Titrating Positive End-Expiratory Pressure on the Prognosis of Acute Respiratory Distress Syndrome in Children. American Journal of Pediatrics. Vol. 4, No. 2, 2018, pp. 41-45. doi: 10.11648/j.ajp.20180402.15

Received: May 31, 2018; Accepted: June 21, 2018; Published: July 24, 2018

\begin{abstract}
To investigate the impact of the optimal respiratory system dynamic compliance (Cdyn) strategy for titrating positive end-expiratory pressure (PEEP) on the prognosis of acute respiratory distress syndrome (ARDS) in children. A total of 30 patients with ARDS admitted in the pediatric intensive care unit (PICU) of Guangxi Maternity and Child Health Hospital were randomly divided into two groups $(n=15)$. PEEP was set in the control group according to the PEEP/ fraction of inspired oxygen $\left(\mathrm{FiO}_{2}\right)$ in American ARDS collaboration network while the optimal Cdyn strategy was employed for the treatment group. We used the pressure control ventilation (PCV) mode and small tidal volume $(7 \mathrm{~mL} / \mathrm{Kg})$. Respiratory mechanics, hemodynamics, and inflammatory cytokines were monitored in each group before and after the experiment. The time of mechanical ventilation, hospital stay in the PICU, and 28-day mortality were compared. There were no significant differences in terms of sex, age, and severity of disease between the two groups. The optimal PEEP of the control group was significant lower than that of the treatment group [(6.4 \pm 1.4$) \mathrm{cmH}_{2} \mathrm{O}$ vs. $\left.(9.9 \pm 1.6) \mathrm{cmH}_{2} \mathrm{O}, \mathrm{P}<0.01\right]$. Cdyn and oxygenation index (OI) in the two groups were improved, and the degree of improvement in the treatment group was significantly higher than that in the control group [Cdyn after the experiment at $2 \mathrm{~h}:(0.39 \pm 0.03) \mathrm{mL} /\left(\mathrm{cmH}_{2} \mathrm{O} . \mathrm{kg}\right)$ vs $(0.36 \pm 0.03) \mathrm{mL} /\left(\mathrm{cmH}_{2} \mathrm{O} . \mathrm{kg}\right), \mathrm{P}<0.05 ; 24 \mathrm{~h}:(0.40 \pm 0.03)$ $\mathrm{mL} /\left(\mathrm{cmH}_{2} \mathrm{O} . \mathrm{kg}\right)$ vs $(0.38 \pm 0.03) \mathrm{mL} /\left(\mathrm{cmH}_{2} \mathrm{O} . \mathrm{kg}\right), \mathrm{P}<0.05 ; 48 \mathrm{~h}:(0.43 \pm 0.02) \mathrm{mL} /\left(\mathrm{cmH}_{2} \mathrm{O} . \mathrm{kg}\right)$ vs. $(0.40 \pm 0.02) \mathrm{mL} /\left(\mathrm{cmH} \mathrm{H}_{2} \mathrm{O} . \mathrm{kg}\right)$, $\mathrm{P}<0.01$; OI after the experiment at $24 \mathrm{~h}:(20.07 \pm 2.12) \mathrm{cmH}_{2} \mathrm{O} / \mathrm{mmHg}$ vs $(21.94 \pm 2.05) \mathrm{cmH}_{2} \mathrm{O} / \mathrm{mmHg}, \mathrm{P}<0.05 ; 48 \mathrm{~h}:(17.51 \pm 1.64)$ $\mathrm{cmH}_{2} \mathrm{O} / \mathrm{mmHg}$ vs $\left.(19.82 \pm 2.07) \mathrm{cmH}_{2} \mathrm{O} / \mathrm{mmHg}, \mathrm{P}<0.01\right]$. There were no significant differences in heart rate, mean arterial pressure, and cardiac index before and after the experiment (all $\mathrm{P}>0.05$ ). Interleukin- 6 (IL-6) in two groups gradually decreased, and the decrease was greater in the treatment group than in the control group [IL-6 after the experiment at $24 \mathrm{~h}:(84.58 \pm 9.11)$ ng/L vs (93.18 \pm 9.27$)$ ng/L, $\mathrm{P}<0.05 ; 48$ h: (76.67 \pm 9.23$) \mathrm{ng} / \mathrm{L}$ vs $(90.10 \pm 9.42) \mathrm{ng} / \mathrm{L}, \mathrm{P}<0.01]$. The length of mechanical ventilation and hospital stay in the PICU was significantly shorter in the treatment than in the control group [length of mechanical ventilation: $(6.62 \pm 1.26)$ days vs $(8.06 \pm 1.44)$ days; hospital stay in the PICU: $(8.12 \pm 1.31)$ days vs $(9.53 \pm 1.42)$ days, all $\mathrm{P}<0.05)$. There was no barotrauma and no difference in mortality between the two groups $(P>0.05)$. The optimal Cdyn method for titrating PEEP improved respiratory mechanics in ARDS, shortened the time of mechanical ventilation, and had no serious adverse effect on hemodynamics.
\end{abstract}

Keywords: Children, Positive End-Expiratory Pressure, Respiratory System Dynamic Compliance, Acute Respiratory Distress Syndrome 


\section{Introduction}

Acute respiratory distress syndrome (ARDS) refers to acute, progressive, and hypoxic respiratory failure caused by pulmonary parenchyma injury during severe infection, trauma, shock, and other conditions. With the continuous improvements in life support technology, the mortality rate of children with ARDS has decreased, but still ranges between $33.7 \%-61.0 \%[1,2]$. Mechanical ventilation remains the preferred treatment modality for ARDS [3]. As is the case for adults, in pediatric ARDS, it is recommended to employ a lung-protective ventilation strategy [4-5], including small tidal volume, appropriate platform pressure, and optimal positive end-expiratory pressure (PEEP). However, the difficulty in clinical application lies in the selection of optimal PEEP, and the most commonly used pressure-volume (P-V) curve method is being increasingly questioned. To this end, this study investigated the impact of employing an optimal respiratory system dynamic compliance (Cdyn) strategy for titrating PEEP on the prognosis of ARDS in children.

\section{Data and Methods}

\subsection{General Data}

We identified 30 patients with ARDS from January 2012 to January 2014 in the pediatric intensive care unit (PICU) of Guangxi Maternity and Child Health Hospital, including 18 boys and 12 girls. The age of the patients ranged from 1 month to 3 years. There were 20 patients between 1 month and 1 year old, six patients between 1 year and 1 month to 2 years old, and four patients between 2 years and 1 month and 3 years old. The primary disease was pneumonia in 18 cases and severe sepsis 12 cases. All patients met the diagnostic criteria of ARDS based on the Berlin definition [6]. All patients could be treated with mechanical ventilation with hemodynamic stability before the intervention, without severe heart failure, shock, thoracic trauma, pneumothorax, increased intracranial pressure, or other complications.

This study met the medical ethics standards, was approved by the ethics committee of our hospital, and the parents of the participants provided informed consent.

\subsection{Group Description}

The initial PEEP was set according to $\mathrm{PEEP} / \mathrm{FiO}_{2}$ in American ARDS collaboration network [7]. After $12 \mathrm{~h}$ of hemodynamic stability, all patients were randomly divided into a control group and a treatment group using the sealed envelope method, with 15 patients allocated to each group. PEEP remained set based on PEEP/ $/ \mathrm{FiO}_{2}$ in American ARDS collaboration network in the control group, while the optimal Cdyn method was employed for the treatment group.

\subsection{Optimal Cdyn Method for Titrating PEEP}

The children were placed in the supine position, intubated, and connected to a MAQUET ventilator for mechanical ventilation. Midazolam was continuously intravenously infused to ensure that the children would remain calm. When necessary, fentanyl or vecuronium was used for sedation, muscle relaxation, and free of spontaneous breathing. The initial PEEP was $0 \mathrm{cmH}_{2} \mathrm{O}$, and PEEP was gradually increased at a frequency of $1 \mathrm{cmH}_{2} \mathrm{O}$. Meanwhile, the peak inspiratory pressure (PIP) was adjusted to maintain a tidal volume of $7 \mathrm{~mL} / \mathrm{kg}$. $\mathrm{FiO}_{2}$ was adjusted to maintain a percutaneous oxygen saturation $\left[\mathrm{Sp}\left(\mathrm{O}_{2}\right)\right]$ greater than $95 \%$ and arterial oxygen partial pressure $\left[\mathrm{Pa}\left(\mathrm{O}_{2}\right)\right] 60-80 \mathrm{mmHg}$. The respiration rate was adjusted to maintain a carbon dioxide partial pressure $\left[\mathrm{Pa}\left(\mathrm{CO}_{2}\right)\right] 35-50 \mathrm{mmHg}$. PEEP was optimal when Cdyn was optimal. The infusion speed remained constant during the test.

\subsection{Observation Items}

The observation items were as follows: (1) general condition of the two groups; (2) respiratory mechanics; the changes in oxygenation index (OI) and Cdyn in the two groups before and after the experiment at $2 \mathrm{~h}, 24 \mathrm{~h}$, and $48 \mathrm{~h}$; (3) hemodynamics; the changes in HR, MAP, and CI of in the two groups before and after the experiment at $1 \mathrm{~h}, 4 \mathrm{~h}$, and $8 \mathrm{~h}$; (4) inflammatory mediators; the changes in IL-6 in the two groups before and after the experiment at $24 \mathrm{~h}$ and $48 \mathrm{~h}$; (5) prognosis; the duration of mechanical ventilation, hospital stay in the PICU, incidence of barotrauma, and 28-day mortality of the two groups.

\subsection{Computational Formula}

$$
\begin{gathered}
\mathrm{OI}=\mathrm{FiO}_{2} \times \text { Pmean }\left(\mathrm{cmH}_{2} \mathrm{O}\right) \times 100 / \mathrm{P}_{\mathrm{a}}\left(\mathrm{O}_{2}\right)(\mathrm{mmHg}) \\
\text { Cdyn }=\mathrm{Vt}(\mathrm{mL}) /(\text { PIP-PEEP }) \times \mathrm{Kg}
\end{gathered}
$$

\subsection{Statistical Method}

SPSS 17.0 (SPSS Inc., Chicago, IL) was used for statistical processing. Data are expressed as $x \pm \mathrm{s}$. We compared continuous variables with independent samples t-test and categorical variables with chi-square and Fisher's exact tests. P $<0.05$ indicates that the difference is statistically significant.

\section{Results}

\subsection{Characteristics of the Two Groups}

There were no statistically significant differences between the two groups in terms of sex, age, and pediatric critical illness score (all, $\mathrm{P}>0.05$ ), as shown in Table 1 .

\subsection{Optimal PEEP in the Two Groups}

According to the $\mathrm{PEEP} / \mathrm{FiO}_{2}$ in American ARDS collaboration network, the optimal PEEP was $(6.4 \pm 1.4)$ $\mathrm{cmH}_{2} \mathrm{O}$; the optimal PEEP determined by Cdyn titration was $(9.9 \pm 1.6) \mathrm{cmH}_{2} \mathrm{O}$. The difference between the two groups was statistically significant $(\mathrm{t}=5.50, \mathrm{P}<0.01)$. 


\subsection{Changes in Respiratory Mechanics and Hemodynamic Indicators in the Two Groups}

Cdyn and OI in the two groups were both improved at $2 \mathrm{~h}$, $24 \mathrm{~h}$, and $48 \mathrm{~h}$, and the degree of improvement in the treatment group was significantly higher than that in the control group. There was no significant change in HR, MAP, and CI between the two groups and in the treatment group before and after the titration (all, $\mathrm{P}>0.05$ ) as shown in Table 2.

\subsection{Comparison of Ventilator-Induced Lung Injury in the Two Groups}

There was no barotrauma, such as pneumothorax, subcutaneous emphysema, and mediastinal emphysema, in either group. Moreover, there was no significant difference in IL- 6 between the two groups before the experiment, and both were progressively reduced after the experiment at $24 \mathrm{~h}$ and 48 $\mathrm{h}$. The reduction was more pronounced in the treatment group, and the difference with the control group was statistically significant as shown in Table 2.

\subsection{Prognosis}

The duration of mechanical ventilation and hospital stay in the PICU in the treatment group was significantly shorter than that in the control group. There was no statistically significant difference between the two groups in 28-day mortality. $(\mathrm{P}>$ 0.05 ) as shown in Table 3.

Table 1. Comparison of the characteristics of children with acute respiratory distress syndrome in the control and treatment groups.

\begin{tabular}{lllll}
\hline Groups & n & Sex (male/female) & Age (months) & Pediatric critical illness score (score) \\
\hline control group & 15 & $8 / 7$ & $7.4 \pm 3.5$ & $76.1 \pm 6.2$ \\
treatment group & 15 & $9 / 6$ & $8.3 \pm 3.7$ & $74.7 \pm 5.3$ \\
t/ $\mathrm{X}^{2}$ value & & 0.14 & 0.43 & 0.45 \\
P value & & $>0.05$ & $>0.05$ & $>0.05$ \\
\hline
\end{tabular}

Table 2. Comparison of respiratory mechanics, hemodynamics, and IL-6 between the control and treatment groups before and after the experiment.

\begin{tabular}{|c|c|c|c|c|c|c|c|c|}
\hline Groups & Time & $\mathbf{n}$ & $\begin{array}{l}\text { Cdyn } \\
{\left[\left(\mathrm{mL} / \mathrm{cmH}_{2} \mathrm{O} . \mathrm{kg}\right)\right]}\end{array}$ & $\begin{array}{l}\text { OI } \\
\left(\mathrm{cmH}_{2} \mathrm{O} / \mathrm{mmHg}\right)\end{array}$ & $\begin{array}{l}\text { HR } \\
\text { (Times/min) }\end{array}$ & $\begin{array}{l}\text { MAP } \\
(\mathrm{mmHg})\end{array}$ & $\begin{array}{l}\mathrm{CI} \\
\left(\mathrm{mL} / \mathrm{cmH}_{2} \mathrm{O}\right)\end{array}$ & $\begin{array}{l}\text { IL-6 } \\
\text { (ng/L) }\end{array}$ \\
\hline \multirow{4}{*}{$\begin{array}{l}\text { control } \\
\text { group }\end{array}$} & base value & 11 & $0.36 \pm 0.03$ & $23.30 \pm 2.37$ & $147.81 \pm 13.12$ & $66.50 \pm 8.56$ & $3.20 \pm 0.15$ & $95.18 \pm 8.24$ \\
\hline & $2 \mathrm{~h}$ after test & 11 & $0.36 \pm 0.03$ & $22.51 \pm 2.20$ & $147.43 \pm 14.12$ & $65.18 \pm 7.32$ & $3.20 \pm 0.25$ & - \\
\hline & $24 \mathrm{~h}$ after test & 11 & $0.38 \pm 0.03$ & $21.94 \pm 2.05$ & $145.09 \pm 15.67$ & $66.73 \pm 6.59$ & $3.22 \pm 0.26$ & $93.18 \pm 9.27$ \\
\hline & $48 \mathrm{~h}$ after test & 11 & $0.40 \pm 0.02$ & $19.82 \pm 2.07$ & $143.27 \pm 15.06$ & $68.36 \pm 6.34$ & $3.18 \pm 0.28$ & $90.10 \pm 9.42$ \\
\hline \multirow{3}{*}{$\begin{array}{l}\text { treatment } \\
\text { group }\end{array}$} & base value & 12 & $0.35 \pm 0.03$ & $23.13 \pm 2.62$ & $148.15 \pm 15.32$ & $65.09 \pm 6.27$ & $3.17 \pm 0.21$ & $96.67 \pm 8.88$ \\
\hline & $2 \mathrm{~h}$ after test & 12 & $0.39 \pm 0.03^{\mathrm{a}}$ & $21.64 \pm 2.69$ & $150.12 \pm 14.80$ & $64.72 \pm 6.82$ & $3.18 \pm 0.24$ & - \\
\hline & $48 \mathrm{~h}$ after test & 12 & $0.43 \pm 0.02^{\mathrm{c}}$ & $17.51 \pm 1.64^{b}$ & $141.84 \pm 13.86$ & $67.52 \pm 6.02$ & $3.27 \pm 0.24$ & $76.67 \pm 9.23^{b}$ \\
\hline
\end{tabular}

IL-6: interleukin-6; Cdyn: respiratory system dynamic compliance; OI: oxygenation index; HR: heart rate; MAP: mean arterial pressure; CI: cardiac index; -: data was not monitored at that time; compared with the control group at the same time, Cdyn: ${ }^{\mathrm{a}} \mathrm{t}=-2.19, \mathrm{P}<0.05 ;{ }^{\mathrm{b}} \mathrm{t}=-2.24, \mathrm{P}<0.05 ;{ }^{\mathrm{c}} \mathrm{t}=-4.59, \mathrm{P}<0.01 ; \mathrm{OI}:{ }^{\mathrm{a}} \mathrm{t}$ $=2.40, \mathrm{P}<0.05 ;{ }^{\mathrm{b}} \mathrm{t}=3.08, \mathrm{P}<0.01 ;$ IL-6: ${ }^{\mathrm{a}} \mathrm{t}=2.25, \mathrm{P}<0.05 ; 48 \mathrm{~h}:{ }^{\mathrm{b}} \mathrm{t}=3.51, \mathrm{P}<0.01$. The values of HR, MAP, and CI are presented $1 \mathrm{~h}, 2 \mathrm{~h}$, and $4 \mathrm{~h}$ before and after the experiment

Table 3. Comparison of prognosis between the control and treatment groups.

\begin{tabular}{lllll}
\hline Groups & n & Mechanical ventilation time (day) & Hospital stay in the PICU (day) & Mortality rate (\%) \\
\hline control group & 15 & $8.06 \pm 1.44$ & $9.53 \pm 1.42$ & 26.67 \\
treatment group & 15 & $6.62 \pm 1.26$ & $8.12 \pm 1.31$ & 2.67 \\
t value & - & 2.49 & $<0.05$ & - \\
P value & - & $<0.05$ & 0.50 \\
\hline
\end{tabular}

The comparison of mortality used Fisher's exact test.

\section{Discussion}

Significant decrease in the gas exchange area caused by alveolar collapse is one of the main pathophysiological features of ARDS. The main purpose of setting PEEP is to maintain the opening of end-expiratory alveoli, increase the gas exchange area and functional residual capacity, and improve oxygenation within a relatively safe $\mathrm{FiO}_{2}(\mathrm{FiO} 2 \leq$ $60 \%$ ) [8-9]. Choosing the right PEEP is key to keeping the alveoli open [10]. Inappropriate PEEP setting can aggravate the patient's ventilator-induced lung injury (VILI); low PEEP causes the alveoli to collapse or repeatedly reexpand/collapse, resulting in atelectrauma and shearing injury, while high PEEP causes the alveoli to overextend, resulting in barotrauma. Providing alveolar stabilization while avoiding harmful distending pressure and pulmonary overdistension is key to avoiding VILI [11]. The current methods of selecting the optimal PEEP are controversial. In clinical study, PEEP is most often selected based on the P-V curve and set near the low inflection point (LIP), but with the further study of the P-V curve, this method was also questioned [12]. The method involves the following: (1) low LIP appearance rate; LIP mainly appears in the acute exudative phase of part alveoli injury, while in the proliferative and fibrosis phases and when there is double lung diffusive injury, there is no obvious LIP turning point. (2) Aggravated VILI; the alveoli are opened in sequence when the $\mathrm{P}-\mathrm{V}$ curve is traced. At pressures as high as 30-40 $\mathrm{cmH}_{2} \mathrm{O}$, PEEP can achieve the opening of all alveoli, 
but alveolar overextension at end inspiration and alveolar collapse at end exhalation may result in VILI aggravation. Xu et al. confirmed that the respiratory mechanics, hemodynamics, and inflammatory factors of ARDS were all worsened after tracing the P-V curve [13]. (3) Operability difference; it is difficult to precisely determine the LIP of the $\mathrm{P}-\mathrm{V}$ curve. Harris et al. found that the differences between observers can be as high as $6-11 \mathrm{cmH}_{2} \mathrm{O}$ when judging the LIP [14].

In ARDS, the pulmonary lesions are heterogeneous and the pressure to reexpand the collapsed alveoli and retain the heterogeneous alveoli open at end exhalation differs. It is impossible to achieve a PEEP suitable for all alveoli. The optimal PEEP may represent a state in which some alveoli are overextended, most alveoli are free of collapse, and the basal alveoli are collapsed. The core of the lung-protective ventilation strategy mainly involves optimal PEEP and small tidal volume, while the small tidal volume ventilation strategy mainly involves limiting the tidal volume to limit the PIP, and thus avoiding the overextension of the alveoli and reducing barotrauma and volutrauma. Therefore, PEEP and PIP should be the two most important breathing parameters to consider in mechanical ventilation. Cdyn is the body's comprehensive response to these two parameter settings. Animal experiments have shown that PEEP can be adjusted according to the changes in Cdyn [15]. Some studies have suggested that the optimal PEEP should be the pressure corresponding to the optimal balance between reexpansion and over distension of the alveoli [13]. Badet et al. indicated that the optimal PEEP can improve the compliance of the respiratory system and increase oxygenation in patients with respiratory failure [16], and the changes in dynamic compliance preceded changes in oxygenation [17]. The PEEP threshold of alveolar collapse set by Cdyn is very consistent with that based on oxygenation [18]. This study also concluded that, while Cdyn in the treatment group was significantly improved compared with the control group, OI was also significantly improved.

When setting the PEEP, it is also important to consider its impact on the circulatory system. The effect of PEEP on the body can be divided into two parts [19-20]: low PEEP is mainly used to expand small airway and collapsed alveoli, improve the ventilation/perfusion ratio, and improve the oxygen supply of tissues. In high PEEP, overextended alveoli increase, intrathoracic pressure is significantly increased, and Cardiopulmonary interaction causes hemodynamic changes, including decreased venous reflux, decreased left and right ventricular filling, and decreased MAP and CI. In this study, PEEP was significantly higher in the treatment group than that in the control group, but the HR, MAP, and CI remained relatively unchanged, indicating that the main function of PEEP with optimal Cdyn is to improve pulmonary compliance and oxygenation function in ARDS, does not cause alveolar overextension which affects the hemodynamics.

It is known that most patients with ARDS do not die due to severe hypoxemia but due to sequential organ function failure (SOFA) [21]. The SOFA score is an independent risk factor predicting death in ARDS [22]. At present, it is believed that the main reason for this is activation of alveolar macrophages caused by VILI, which promotes the production and release of pulmonary inflammatory mediators. Monitoring the changes in inflammatory factors in the body will help detect VILI earlier [23-24]. In this study, there was no barotrauma in either group, but the decrease in IL-6 in the treatment group was significantly higher than that in the control group. This indicates that the optimal Cdyn method for titrating PEEP can significantly reduce the systemic inflammatory response mediated by macrophage activation. Regarding prognosis, the optimal Cdyn method for titrating PEEP can significantly shorten mechanical ventilation time and hospital stay in the PICU in patients with ARDS. There was no significant difference in mortality between the two groups, which may be related to the small sample size, and large-sample, multi-center studies are needed to further confirm our findings.

\section{Conclusion}

The optimal Cdyn method for titrating PEEP can significantly improve the respiratory mechanics of children with ARDS and alleviate the effect of VILI on hemodynamics. Besides, the requirements on the ventilator for the implementation of this method are not high, and it is easy to operate and perform.

\section{References}

[1] Schouten LR, Veltkamp F, Bos AP, van Woensel JB, Serpa Neto A, Schultz MJ, et al. Incidence and mortality of acute respiratory distress syndrome in childen: a systematic review and Meta-analysis. Crit Care Med 2016; 44: 819-29.

[2] Yu WL, Qian SY, Zhu YR, Hou XG, Li M, Tang DH, et al. Prospective, multicenter study of mortality and risk factors in children with acute respiratory distress syndrome in 25 pediatric intensive care units in China. Zhonghua Yi Xue Za Zhi 2007; 87: 3295-7.

[3] Liu J, Wang W, Liu F, Li Z. Pediatric acute respiratory distress syndrome - current views. Exp Ther Med 2018; 15: 1775-80.

[4] Pediatric Acute Lung Injury Consensus Conference Group. Pediatric acute respiratory distress syndrome: consensus recommendations from the Pediatric Acute Lung Injury Consensus Conference. Pediatr Crit Care Med 2015; 16: 428-39.

[5] Heidemann SM, Nair A, Bulut Y, Sapru A. Pathophysiology and Management of Acute Respiratory Distress Syndrome in Children. Pediatr Clin North Am 2017; 64: 1017-37.

[6] ARDS definition Task Force, Ranieri VM, Rubenfeld GD, Thompson BT, Ferguson ND, Caldwell E, et a1. Acute respiratory distress syndrome: The Berlin Definion. JAMA 2012; 307: 2526-33.

[7] Acute Respiratory Distress Syndrome Network, Brower RG, Matthay MA, Morris A, Schoenfeld D, Thompson BT, et al. Ventilation with lower tidal volumes as compared with traditional tidal volumes for acute lung injury and the acute respiratory distress syndrome. N Engl J Med 2000; 342: 1301-8. 
[8] Li XF, You WY, Zhu GY, Zeng JQ. Effects of PEEP by using the inflection point of maximum curvature of the pressure-volume curves deflation limb on oxygenation and hemodynamics in ARDS patients. Chin J Crit Care Med 2012; 32: $586-8$.

[9] Chiew YS, Chase JG, Shaw GM, Sundaresan A, Desaive T. Model-based PEEP optimisation in mechanical ventilation. Biomed Eng Online 2011; 10: 111.

[10] Guerin C. The preventive role of higher PEEP in treating severely Hypoxemic ARDS. Minerva Anestesiol 2011; 77: 835-45.

[11] Klapsing P, Moerer O, Wende C, Herrmann P, Quintel M, Bleckmann A, et al. High-frequency oscillatory ventilation guided by transpulmonary pressure in acute respiratory syndrome: an experimental study in pigs. Crit Care 2018; 22: 121.

[12] Spieth PM, Gama de Abreu M. Lung recruitment in ARDS: We are still confused, but on a higher PEEP level. Crit Care 2012; 16: 108 .

[13] Xu L, Feng QS, Lian F, Shao XH, Li ZB, Wang ZY, et al. Clinical research of using optimal compliance to determine positive end-expiratory pressure. Chin Crit Care Med 2012; 24: 393-7.

[14] Harris RS, Hess DR, Venegas JG. An objective analysis of the pressure-volume curve in the acute respiratory distress syndrome. Am J Respir Crit Care Med 2000; 161: 432-9.

[15] Suarez-Sipmann F, Böhm SH, Tusman G, Pesch T, Thamm O, Reissmann $\mathrm{H}$, et a1. Use of dynamic compliance for open lung positive end-expiratory pressure titration in an experimental study. Crit Care Med 2007; 35: 214-21.

[16] Badet M, Bayle F, Richard JC, Guérin C. Comparison of optimal positive end- expiratory pressure and recrument maneuvers during lung-protective mechanical ventilation in patients with acute lung injury/acute respiratory distress syndrome. Respir Care 2009; 54: 847-54.
[17] Smallwood CD, Walsh BK, Arnold JH, Gouldstone A. Equilibration Time Required for Respiratory System Compliance and Oxygenation Response Following Changes in Positive End-Expiratory Pressure in Mechanically Ventilated Children. Crit Care Med 2018; 46: e375-9.

[18] Ganzert S, Kramer S, Guttmann J. Predicting the lung compliance of mechanically ventilated patients via statistical modeling. Physiol Meas 2012; 33: 345-59.

[19] Pinsky MR. My paper 20 years later: Effect of positive end-expiratory pressure on right ventricular function in humans. Intensive Care Med 2014; 40: 935-41.

[20] Van de Louw A, Médigue C, Papelier Y, Cottin F. Positive end-expiratory pressure may alter breathing cardiovasonlar variability and baroreflex gain in mechanically ventilated patients. Respir Res 2010; 11: 38 .

[21] El-Nawawy A, Moustafa A, Heshmat H, Abouahmed A. High frequency oscillatory ventilation versus conventional mechanical ventilation in pediatricacute respiratory distress syndrome: A randomized controlled study. Turk J Pediatr 2017; 59: $130-43$.

[22] Ye SM, Liang ZX, Li Y, Chen LA. Stratified analysis of predictors of in-hospital mortality in 189 patients with ARDS. Int J Respir 2013; 33: 533-6.

[23] Villar J, Kacmarek RM, Pérez-méndez L, Aguirre-Jaime A. A high positive end-expiratory pressure, low tidal volume ventilator strategy improves outcome in persistent acute respiratory distress syndrome: a randomized controlled trial. Crit Care Med 2006; 34: 1311-8.

[24] Yang CY, Chen CS, Yiang GT, Cheng YL, Yong SB, Wu MY, et al. New Insights into the Immune Molecular Regulation of the Pathogenesis of Acute Respiratory Distress Syndrome. Int J Mol Sci 2018; 19. pii: E588. 